\title{
DIFFUSION-WEIGHTED-IMAGING INFARCT VOLUME MEASUREMENT TOOLS SHOW DISCREPANCIES LEADING TO DIVERGING THROMBECTOMY DECISIONS
}

Naïm KHOURY, MD 1; Cyril DARGAZANLI, MD MSc 2; Kevin ZUBER, MSc ${ }^{3}$; Célina DUCROUX, MD MSc ${ }^{3}$; Raphaël BLANC, MD MSc ${ }^{3}$; Michel PIOTIN, MD PhD ${ }^{3}$; Robert FAHED, MD MSc ${ }^{3}$

(1) HSHS Neuroscience Center, HSHS St. John's Hospital - Springfield - IL - USA

(2) Interventional Neuroradiology Department - Hôpital Gui de Chauliac - Montpellier - FRANCE

(3) Interventional Neuroradiology Department - Fondation Rothschild Hospital - Paris - France

\section{Introduction}

DAWN and DEFUSE-3 trials demonstrated the benefit of thrombectomy beyond 6 hours based on the automated measurement of infarct volume exclusively with the RAPID software. However, RAPID is not accessible in all centers, and it is currently unknown whether using other tools than RAPID would lead to similar infarct volume measurements. We aimed to compare nine tools commonly used for the measurement of infarct volume and see whether they would lead to similar thrombectomy decisions based on the DAWN trial imaging inclusion criteria.

\section{Methods}

The diffusion-weighted-imaging (DWI) infarct volume of 36 patients was measured with 3 automated tools (including RAPID) and 6 non-automated tools. The agreement for the measurements of DWI infarct volume and the resulting thrombectomy decisions were assessed with intraclass correlation coefficient (ICC) and Fleiss' Kappa (K) statistics.

\section{Results}

The correlation for the measurement of DWI infarct volume between all 9 tools was excellent (Figure A). After dichotomization, agreement was substantial for any of the cutpoint used in DAWN trial (Figure B). Discrepancies involving at least one of the tools for thrombectomy decisions based on DAWN criteria occurred in more than $35 \%$ of cases. Compared with RAPID, the use of any other tool for treatment decision based on DAWN criteria would have led to contradictory decisions in $6 \%$ to $19 \%$ of cases (Table 1 ).

A

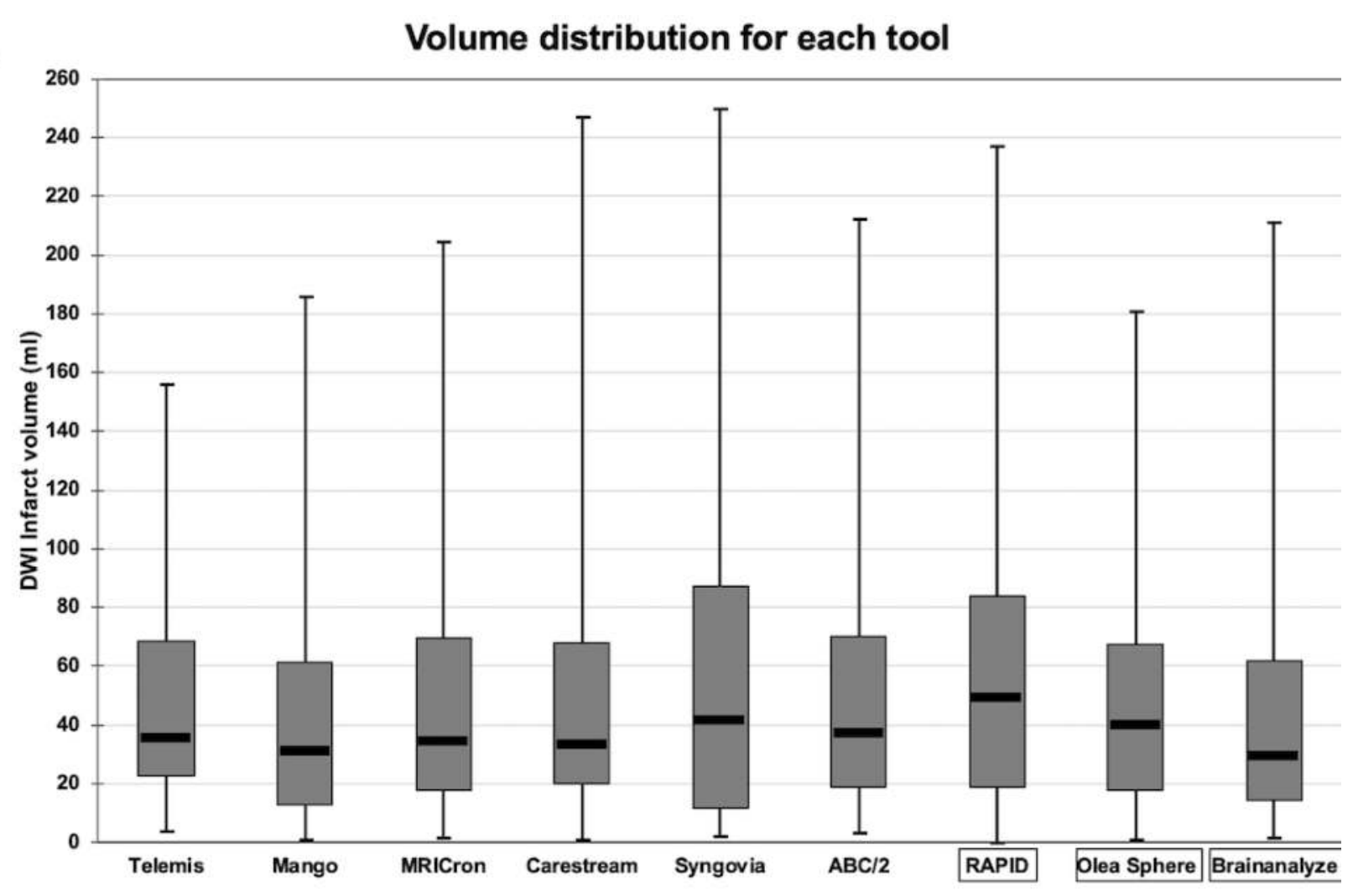

\section{Conclusion}

There are several currently available tools for the measurement of DWI infarct volume with excellent correlation. Despite the high agreement demonstrated in our study, frequent discrepancies between measurements in some dichotomized configurations led to frequent diverging thrombectomy decisions when applying DAWN criteria. Physicians should be aware of the existence of such discrepancies when using one of these tools instead of RAPID for the strict application of DAWN criteria.

Table 1: Comparison of each tool with RAPID as reference standard: mean $\pm S D$ difference for DWI infarct volume measurement $(\mathrm{ml})$, and number of contradictory thrombectomy decisions based on DAWN criteria.

\begin{tabular}{|l|c|c|}
\hline Tool & $\begin{array}{c}\text { Mean } \pm \text { SD } \\
\text { difference }\end{array}$ & $\begin{array}{c}\text { Number of contradictory } \\
\text { thrombectomy decisions } \\
\text { with RAPID (mI) }\end{array}$ \\
\hline Telemis & $9.7 \pm 23.1$ & $5 / 36(13.9 \%)$ \\
\hline Mango & $19.1 \pm 20.4$ & $4 / 36(11.1 \%)$ \\
\hline MRICron & $10.3 \pm 15.6$ & $4 / 36(11.1 \%)$ \\
\hline Carestream & $11.2 \pm 18.3$ & $7 / 36(19.4 \%)$ \\
\hline Syngovia & $2.6 \pm 18.1$ & $3 / 36(8.3 \%)$ \\
\hline ABC/2 & $9.9 \pm 22.8$ & $6 / 36(16.7 \%)$ \\
\hline Olea Sphere & $9.0 \pm 15.2$ & $2 / 36(5.5 \%)$ \\
\hline Brainanalyze & $13.4 \pm 19.1$ & $6 / 36(16.7 \%)$ \\
\hline
\end{tabular}

B

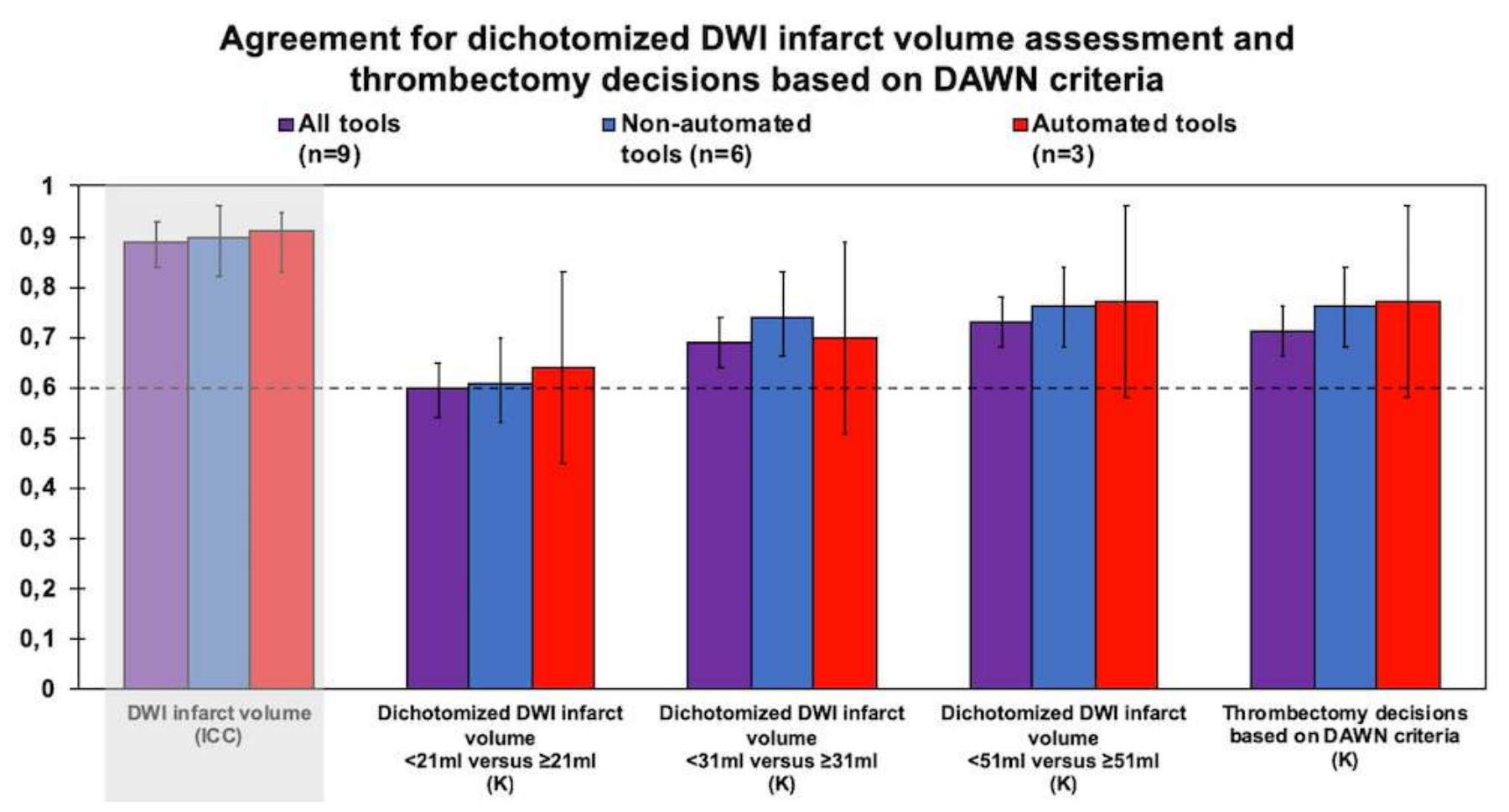

